\title{
ANALISIS STRATEGI PENGEMBANGAN PERIKANAN PELAGIS DI KABUPATEN BANYUASIN PROVINSI SUMATERA SELATAN
}

\author{
Dwi Rosalina \\ Jurusan Perikanan, Fakultas Pertanian, Perikanan dan Biologi, Universitas Bangka Belitung \\ Gedung Babel IV Kampus Terpaunijuk, Kabupaten Bangka
}

Diterima 22 November 2011 - Disetujui 11 Desember 2011

\begin{abstract}
ABSTRAK
Kajian ini merupakan analisa pengembangan strategi perikanan pelagis di Kabupaten Banyuasin. Kajian ini bertujuan untuk (i) menentukan teknologi penangkapan ikan pelagis yang efektif, efisien dan berkelanjutan berdasarkan aspek biologi, teknis, sosial, ekonomi, dan keramahan lingkungan; (ii) menentukan alokasi jumlah unit penangkapan ikan pelagis yang optimum; dan (iii) menentukan strategi pengembangan alat tangkap ikan pelagis. Kajian ini menggunakan metode pemeringkatan (scoring), analisa optimum, analisa finansial usaha serta analisa SWOT. Hasil kajian menunjukkan bahwa rawai hanyut merupakan teknologi penangkapan ikan yang relatif lebih efektif, efisien dan berkelanjutan daripada alat tangkap jaring insang hanyut dan bagan tancap. Alokasi unit penangkapan rawai hanyut yang direkomendasikan sebanyak 51 unit. Hasil analisis kelayakan usaha alat tangkap rawai hanyut di Kabupaten Banyuasin menunjukkan keuntungan Rp. 18.767.666, nilai NPV Rp. 55.855.075, Net B/C sebesar 2,22 dan nilai BEP untuk nilai produksi per tahun Rp. 39.055 .258 dan volume produksi per tahun $23.669 \mathrm{~kg}$, nilai ROI $41 \%$, nilai IRR $48 \%$. Strategi pengembangan alat tangkap pelagis kecil di Kabupaten Banyuasin yang disarankan adalah (i) optimalisasi usaha perikanan pelagis; (ii) pengembangan usaha perikanan pelagis di jalur 6 - 10 mil laut; (iii) peningkatan manajemen usaha perikanan pelagis; (iv) peningkatan skala usaha armada penangkapan ikan pelagis; dan (v) pembenahan fasilitas sarana dan prasarana perikanan.
\end{abstract}

Kata Kunci: rawai hanyut, jaring ingsang hanyut, bagan tancap, skoring, strategi pengembangan perikanan pelagis, Banyuasin

\section{Abstract: Analysis of Strategy for Pelagic Fishery Development in the Banyuasin Regency of South Sumatera Province. By: Dwi Rosalina}

This research is an analysis strategy for pelagic fishery development in the Banyuasin Regency of South Sumatera Province. The objectives of the research (i) to determine more effective, efficient and sustainable fishing technology for pelagic fish based on biological, technical, social, economic and environment aspects; (ii) to assess optimum allocation for pelagic fish catching unit; and (iii) to determine development strategy of pelagic fisheries. This research used scoring method, optimum allocation, financial and SWOT analysis. This research results indicated that drift long-line fishing technology is more effective, efficient and sustainable than drift gillnet and lift-net. Suggested numbers of optimum allocation of fishing unit consist of 51 unit drift long-line. Output of feasibility analysis of drift long-line fishery indicated profit of IDR $18,767,666, N P V$ value was IDR 55,855,075, Net B/C was 2.22 , the BEP value was IDR $39,055,258$ that equal to production $23,669 \mathrm{~kg}$, the $R O I$ and IRR value were $41 \%$ and 48 . This research suggested following development strategies of pelagic fisheries in Banyuasin Regency namely (i) optimization of drift long-line for pelagic fishery, (ii) focussing development pelagic fish fishery in 6-12 mile zone; (iii) increasing management effort of fisheries business; (4) revitalization of fisheries infrastructures and facilities; and (v) empowering scale of fishing fleet and its technology.

Keywords: drift long-line, drift gillnet, lift-net, scoring, pelagic fishery development strategy, Banyuasin 


\section{PENDAHULUAN}

Pengembangan penangkapan ikan pada hakikatnya mengarah ke pemanfaatan sumber daya ikan secara optimal dan rasional bagi kesejahteraan masyarakat pada umumnya dan nelayan khususnya, tanpa menimbulkan kerusakan sumber daya ikan itu sendiri maupun lingkungannya. Potensi perikanan Kabupaten Banyuasin tergolong lengkap mulai dari usaha penangkapan ikan di laut dan perairan umum hingga budidaya perikanan di air payau, air tawar maupun budidaya ikan di laut. Karena itu, tidaklah mengherankan bila daerah ini sangat mengandalkan nelayan dan UKM Perikanan lainnya sebagai penggerak pertumbuhan ekonomi kerakyatan, disamping sektor usaha agribisnis dan pertambangan.

Selain kaya akan sumberdaya ikan, perairan pantai Kabupaten Banyuasin juga kaya akan berbagai jenis udang terutama udang windu, jerbung, udang dogol, kepiting bakau serta kerang dan rajungan. Secara keseluruhan, daerah yang memiliki perairan laut seluas $1.765,4 \mathrm{~km}^{2}$ dan garis pantai sepanjang $275 \mathrm{~km}$ ini, memiliki potensi perikanan laut sebanyak 102.300 ton, namun saat ini produksinya baru sebesar 49.399 ton atau $48,3 \%$ saja tingkat pemanfaatannya. Potensi lahan tambak udang dan bandeng sebesar 21.000 ha, dan saat ini baru dimanfaatkan 3.272 ha, serta dari 142.000 ha potensi lahan budidaya air tawar, baru dapat dikelola 8.520 ha (Anonim, 2006).

Produksi ikan pelagis yang tercatat pada tahun 2006 sebesar 29,62 ton/tahun, sementara potensi ikan pelagis Kabupaten Banyuasin memiliki potensi ikan demersal 32.800 ton/tahun dan ikan pelagis 60.000 ton/tahun. Hal ini didukung oleh kegiatan perikanan yang berkembang di Kabupaten Banyuasin adalah kegiatan perikanan tangkap (Anonim, 2006).

Usaha perikanan yang berkembang di Kabupaten Banyuasin masih tergolong perikanan pantai, di mana kegiatan penangkapan ikannya hanya dilakukan di sekitar perairan pantai. Alat tangkap yang umumnya digunakan nelayan untuk menangkap ikan pelagis di daerah ini adalah jaring insang hanyut, rawai hanyut dan bagan tancap. Namun kajian yang terkait dengan teknologi penangkapan ikan pelagis berdasarkan aspek biologi, teknis, sosial, ekonomi dan keramahan lingkungan, jumlah unit penangkapan ikan pelagis yang optimum dan kajian mengenai strategi pengembangan alat tangkap ikan pelagis belum pernah dilakukan, maka sangat perlu untuk dilakukan penelitian tentang pengembangan perikanan tangkap berbasis optimasi sumber daya ikan pelagis di Kabupaten Banyuasin Propinsi Sumatera Selatan, sehingga dengan penelitian ini diharapkan usaha perikanan di wilayah Kabupaten Banyuasin dapat dilakukan secara optimal tanpa mengganggu kelestarian sumberdaya yang ada.

Tujuan penelitian ini adalah menentukan teknologi penangkapan ikan pelagis yang efektif, efisien dan berkelanjutan berdasarkan aspek biologi, teknis, sosial, ekonomi, dan keramahan lingkungan di Kabupaten Banyuasin Propinsi Sumatera Selatan; mengalokasikan jumlah unit penangkapan ikan pelagis yang optimum; dan menentukan strategi pengembangan teknologi penangkapan perikanan pelagis di Kabupaten Banyuasin.

\section{METODOLOGI}

Penelitian ini dilakukan pada tahun 2009 di Sungsang, Kabupaten Banyuasin, Propinsi Sumatera Selatan. Penelitian ini dilakukan dengan menggunakan metode survei dan observasi lapangan. Data yang di kumpulkan adalah data primer dan data sekunder. Pengumpulan data primer dilakukan melalui pengukuran dan pengamatan langsung terhadap unit penangkapan ikan pelagis serta wawancara menggunakan daftar pertanyaan yang sesuai dengan tujuan penelitian. Wawancara dilakukan terhadap nelayan pemilik alat penangkapan ikan pelagis, nelayan sebagai pekerja dan para stakeholder perikanan tangkap di Kabupaten Banyuasin. Data sekunder diperoleh dari Dinas Perikanan dan Kelautan Propinsi Sumatera Selatan, Dinas Perikanan dan Kelautan Kabupaten Banyuasin, dan berbagai tulisan melalui penelusuran pustaka (studi pustaka). 
Analisis yang digunakan dalam penelitian ini adalah metode skoring yang tujuannya adalah menetapkan prioritas unit penangkapan ikan pelagis terpilih. Selanjutnya, analisis finansial bertujuan untuk menentukan kelayakan usaha alat tangkap yang ada. Kemudian dilakukan pengalokasian unit penangkapan ikan pelagis dengan menggunakan model linear goal programming untuk mengetahui jumlah alokasi dari alat tangkap dan untuk melihat strategi pengembangan perikanan tangkap menggunakan analisis SWOT.

\section{Metode skoring}

Rumus matematis yang digunakan untuk menetapkan prioritas unit penangkapan ikan menurut Mangkusubroto dan Trisnadi 1985) adalah:

$$
\begin{aligned}
& V(X)=\frac{X-X_{0}}{X_{a}-X_{0}} \\
& V(A)=\sum_{i=a}^{n} V i(X i) \\
& i=a, b, c, d \ldots \ldots . . n
\end{aligned}
$$

\section{Keterangan :}

$$
\begin{aligned}
V(X)= & \text { Fungsi nilai dari variabel } X / \text { Value } \\
& \text { function of variable } X \\
X \quad= & \text { Nilai variabel } X / \text { Variable } X \text { value } \\
X_{a}= & \text { Nilai tertinggi pada kriteria } X / \text { Highest } \\
& \text { value of criteria } X \\
X_{0} \quad & \text { Nilai terendah pada kriteria } X / \text { Lowest } \\
& \text { value of criteria } X \\
V(A)= & \text { Fungsi nilai dari alternatif } A / \text { Value } \\
& \text { function of alternative } A \\
V_{i}\left(X_{i}\right)= & \text { Fungsi nilai dari alternatif pada kriteria } \\
& \text { ke- } i / \text { Value function of criteria } i
\end{aligned}
$$

\section{Analisis finansial}

Analisis finansial adalah suatu analisis proyek dimana proyek dilihat dari sudut badan-badan atau orang-orang yang menanam modalnya dalam proyek atau yang berkepentingan langsung dalam proyek (Kadariah et al., 1981). Analisis finansial yang digunakan adalah analisis usaha dan analisis kriteria investasi.

\section{Optimasi alokasi unit penangkapan}

Pengembangan perikanan tangkap adalah mengoptimalkan alokasi armada penangkapan secara bersamaan yang dibatasi oleh berbagai kendala dengan menggunakan model goal programming. Menurut Stevenson (1989), goal proramming merupakan variasi dari model linear programming yang dapat digunakan untuk menangani masalah yang mempunyai banyak sasaran. Selanjutnya Siswanto (1993), mengatakan bahwa dalam model goal programming terdapat variabel deviasional dalam fungsi kendala. Variasi tersebut berfungsi untuk menampung penyimpangan hasil penyelesaian terhadap sasaran yang hendak dicapai, dimana dalam proses pengolahan model tersebut jumlah variabel deviasional akan diminimumkan di dalam fungsi tujuan.

\section{Analisis SWOT (Strengths, Weaknesses, Opportunities and Threats)}

Analisis SWOT didasarkan pada asumsi bahwa strategi yang efektif adalah dengan memaksimalkan kekuatan (Strengths) dan peluang (Opportunities), serta meminimalkan kelemahan (Weaknesses) dan ancaman (Threats). Analisis ini didahului oleh proses identifikasi faktor eksternal dan internal. Untuk menentukan strategi yang terbaik, dilakukan pembobotan terhadap tiap unsur SWOT berdasarkan tingkat kepentingan.

\section{PEMILIHAN TEKNOLOGI PERIKANAN TANGKAP}

Asumsi dari pemilihan teknologi perikanan tangkap yaitu skoring diberikan dengan nilai terendah sampai nilai tertinggi. 
Untuk nilai tertinggi diberikan urutan prioritas 1 begitupun seterusnya. Dalam menilai semua kriteria atau aspek yang digunakan nilai tukar, sehingga semua nilai mempunyai standar yang sama. Jenis alat tangkap yang memperoleh nilai tertinggi berarti lebih baik daripada yang lainnya, demikian juga sebaliknya.

\section{Analisis aspek biologi}

Penilaian keunggulan unit penangkapan ikan pelagis dilihat dari aspek biologi (Tabel 1) menempatkan rawai hanyut pada urutan prioritas pertama. Hal ini karena alat tangkap rawai hanyut menggunakan umpan yang mengakibatkan ikan pelagis lebih tertarik. Hal ini lebih diperkuat oleh pendapat Sadhori (1985) mengatakan umpan merupakan salah satu faktor yang sangat besar pengaruhnya terhadap keberhasilan dalam usaha penangkapan baik masalah jenis umpan, sifat umpan maupun cara ikan memakan umpan.

\section{Analisis aspek teknis}

Penilaian keunggulan berdasarkan aspek teknis, pada unit penangkapan ikan pelagis menempatkan rawai hanyut pada prioritas pertama. Penggunaan umpan pada rawai hanyut yang menyebabkan ikan pelagis tertarik untuk memakan umpan pada pancing rawai dan produksi per tahun dari rawai hanyut lebih besar dari jaring insang hanyut dan bagan tancap sebesar $48000 \mathrm{~kg}$ per tahunnya, dapat dilihat pada Tabel 2 .

\section{Analisis aspek sosial}

Penilaian keunggulan unit penangkapan ikan pelagis berdasarkan aspek sosial menempatkan rawai hanyut pada urutan prioritas pertama. Seperti yang sudah dibahas pada aspek biologi dan teknis, ternyata rawai hanyut memiliki jumlah produksi yang melebihi jumlah produksi jaring insang hanyut dan bagan tancap, dapat dilihat pada Tabel 3.

Tabel 1. Skoring dan Standarisasi Fungsi Nilai Aspek Biologi Unit Penangkapan Ikan Pelagis di Kabupaten Banyuasin.

Table 1. Scoring and Standardization of Biological Value Function Aspect of Pelagic Fishing Unit in Banyuasin Regency.

\begin{tabular}{|c|c|c|c|c|c|c|c|c|}
\hline \multirow{2}{*}{$\begin{array}{l}\text { Unit Penangkapan } \\
\text { Ikan Pelagis/ Pelagic } \\
\text { Fish Fishing Units }\end{array}$} & \multicolumn{6}{|c|}{ Kriteria Penelitian/ Research Point Criteria } & \multirow[b]{2}{*}{$V(A) 1$} & \multirow[b]{2}{*}{ UP } \\
\hline & $\mathrm{x} 1$ & V1(X1) & $\mathrm{X} 2$ & V2(X2) & X3 & V3(X3) & & \\
\hline $\begin{array}{l}\text { Rawai Hanyut/ Drift } \\
\text { Longline }\end{array}$ & 55 & 1 & 21 & 1 & 9 & 1 & 3 & 1 \\
\hline $\begin{array}{l}\text { Jaring Insang Hanyut/ } \\
\text { Drift Gillnet }\end{array}$ & 50 & 0.75 & 19 & 0.69 & 8 & 0.5 & 1.94 & 2 \\
\hline Bagan Tancap/ Liftnet & 35 & 0 & 14.5 & 0.0 & 7 & 0 & 0.0 & 3 \\
\hline
\end{tabular}

Sumber : Data primer diolah, 2009.

Source : Primary data processed, 2009.

Keterangan :

$\mathrm{X} 1=$ Komposisi target spesies/ Target species composition

$\mathrm{V} 1(\mathrm{X} 1)=$ Nilai alat tangkap kali jumlah kriteria aspek/ Fishing gear value cross aspect criteria summary

$\mathrm{X} 2=$ Ukuran panjang ikan/ Fish measure length

$\mathrm{V} 1(\mathrm{X} 2)=$ Nilai alat tangkap kali jumlah kriteria aspek/ Fishing gear value cross aspect criteria summary

X3 = Musim penangkapan ikan/ Fishing season

$\mathrm{V} 1(\mathrm{X} 3)=$ Nilai alat tangkap kali jumlah kriteria aspek/ Fishing gear value cross aspect criteria summary

$\mathrm{V}(\mathrm{A})^{1}=$ Hasil scoring/ Scoring

UP $\quad=$ Urutan prioritas/ Priority 
Tabel 2. Skoring dan Standarisasi Fungsi Nilai Aspek Teknis Unit Penangkapan Ikan Pelagis di Kabupaten Banyuasin.

Table 2. Scoring and Standardization of Technical Value Function Aspect of Pelagic Fishing Unit in Banyuasin Regency.

\begin{tabular}{|c|c|c|c|c|c|c|c|c|}
\hline \multirow{2}{*}{$\begin{array}{l}\text { Unit Penangkapan } \\
\text { Ikan Pelagis/ Pelagic } \\
\text { Fish Fishing Units }\end{array}$} & \multicolumn{6}{|c|}{ Kriteria Penelitian/ Research Point Criteria } & \multirow{2}{*}{$V(A) 2$} & \multirow{2}{*}{ UP } \\
\hline & $\mathbf{x 1}$ & V1(X1) & $\mathbf{x} 2$ & V2(X2) & $\mathrm{X} 3$ & V3(X3) & & \\
\hline $\begin{array}{l}\text { Rawai Hanyut/ Drift } \\
\text { Longline }\end{array}$ & 48,000 & 1 & 300 & 1 & 60 & 1 & 3 & 1 \\
\hline $\begin{array}{l}\text { Jaring Insang Hanyut/ } \\
\text { Drift Gillnet }\end{array}$ & 38,400 & 0.64 & 200 & 0.46 & 55 & 0.75 & 1.85 & 2 \\
\hline Bagan Tancap/ Liftnet & 21,600 & 0 & 115 & 0 & 40 & 0 & 0 & 3 \\
\hline
\end{tabular}

Sumber : Data primer diolah, 2009.

Source : Primary data processed, 2009.

Keterangan :

$\mathrm{X} 1=$ Produksi per tahun/ Production per year

$\mathrm{V} 1(\mathrm{X} 1)=$ Nilai alat tangkap kali jumlah kriteria aspek/ Fishing gear value cross aspect criteria summary

$\mathrm{X} 2=$ Produksi per trip/Production per trip

$\mathrm{V} 1(\mathrm{X} 2)=$ Nilai alat tangkap kali jumlah kriteria aspek/ Fishing gear value cross aspect criteria summary

$\mathrm{X} 3=$ Produksi per tenaga kerja/ Production per employee

$\mathrm{V} 1(\mathrm{X} 3)=$ Nilai alat tangkap kali jumlah kriteria aspek/ Fishing gear value cross aspect criteria summary

$\mathrm{V}(\mathrm{A})^{2}=$ Hasil skoring/ Scoring

UP $\quad=$ Urutan prioritas/Priority

Tabel 3. Skoring dan Standarisasi Fungsi Nilai Aspek Sosial Unit Penangkapan Ikan Pelagis di Kabupaten Banyuasin.

Table 3. Scoring and Standardization of Social Value Function Aspect of Pelagic Fishing Unit in Banyuasin Regency.

\begin{tabular}{|c|c|c|c|c|c|c|c|c|}
\hline \multirow{2}{*}{$\begin{array}{l}\text { Unit Penangkapan } \\
\text { Ikan Pelagis/ Pelagic } \\
\text { Fish Fishing Units }\end{array}$} & \multicolumn{6}{|c|}{ Kriteria Penelitian/ Research Point Criteria } & \multirow[b]{2}{*}{$V(A) 3$} & \multirow[b]{2}{*}{ UP } \\
\hline & X1 & $\mathrm{V} 1(\mathrm{X} 1)$ & $\mathbf{X} 2$ & V2(X2) & X3 & V3(X3) & & \\
\hline $\begin{array}{l}\text { Rawai Hanyut/ Drift } \\
\text { Longline }\end{array}$ & 4 & 1 & $40,000,000$ & 1 & 1 & 0 & 2 & 1 \\
\hline $\begin{array}{l}\text { Jaring Insang Hanyut/ } \\
\text { Drift Gillnet }\end{array}$ & 4 & 1 & $32,000,000$ & 0.64 & 1 & 0 & 1.64 & 2 \\
\hline Bagan Tancap/ Liftnet & 3 & 0 & $18,000,000$ & 0 & 2 & 1 & 1 & 3 \\
\hline
\end{tabular}

Sumber : Data primer diolah, 2009.

Source : Primary data processed, 2009.

Keterangan :

$\mathrm{X} 1=$ Jumlah tenaga kerja per unit penangkapan ikan/ Total employee per fishing unit

$\mathrm{V} 1(\mathrm{X} 1)=$ Nilai alat tangkap kali jumlah kriteria aspek/ Fishing gear value cross aspect criteria summary

X2 = Pendapatan nelayan per tahun/ Fisherman income per year

$\mathrm{V} 1(\mathrm{X} 2)=$ Nilai alat tangkap kali jumlah kriteria aspek/ Fishing gear value cross aspect criteria summary

$\mathrm{X3}=$ Tingkat penguasaan teknologi/ Mastery level of technology

$\mathrm{V} 1(\mathrm{X} 3)=$ Nilai alat tangkap kali jumlah kriteria aspek/ Fishing gear value cross aspect criteria summary

$\mathrm{V}(\mathrm{A})^{3}=$ Hasil skoring/ Scoring

UP = Urutan prioritas/Priority 


\section{Analisis aspek ekonomi}

Penilaian keunggulan unit penangkapan ikan pelagis berdasarkan aspek ekonomi menempatkan rawai hanyut pada urutan prioritas pertama. Seperti yang telah dianalisis pada beberapa aspek sebelumnya bahwa produksi rawai hanyut yang lebih besar dari jaring insang hanyut dan bagan tancap menyebabkan penerimaan rawai hanyut juga lebih besar daripada penerimaan jaring insang hanyut dan bagan tancap, dapat dilihat pada Tabel 4.

\section{Analisis aspek keramahan lingkungan}

Berdasarkan hasil skoring maka alat tangkap rawai hanyut termasuk kategori alat tangkap yang ramah lingkungan sedangkan bagan tancap dan jaring insang hanyut termasuk alat tangkap yang kurang ramah lingkungan, dapat dilihat pada Tabel 5.
Menurut Ayodhyoa (1981) menyatakan bahwa rawai hanyut pada umumnya dioperasikan pada perairan yang dangkal untuk menangkap jenis-jenis ikan pelagis (seperti tongkol, cakalang, layang, selar, dan baby tuna). Alat tangkap pancing ini termasuk kategori ramah lingkungan karena walaupun dioperasikan dikolom perairan, namun tidak merusak habitat ikan, karena dimensinya hanya mempengaruhi atau mencakup areal yang kecil dan alat tangkap ini juga sangat selektif terhadap jenis dan ukuran ikan, sehingga tidak mengganggu siklus hidup dan pertumbuhan populasi ikan.

Menurut pendapat Samuel (2003) mengatakan bahwa alat tangkap jaring tergolong alat tangkap yang produktif, tetapi tidak ramah terhadap keseimbangan populasi ikan yang ditangkap.

Tabel 4. Skoring dan Standarisasi Fungsi Nilai Aspek Ekonomi Unit Penangkapan Ikan Pelagis di Kabupaten Banyuasin.

Table 4. Scoring and Standardization of Economic Value Function Aspect of Pelagic Fishing Unit inBanyuasin Regency.

\begin{tabular}{|c|c|c|c|c|c|c|c|c|}
\hline \multirow{2}{*}{$\begin{array}{l}\text { Unit Penangkapan } \\
\text { Ikan Pelagis/ } \\
\text { Pelagic Fish } \\
\text { Fishing Units }\end{array}$} & \multicolumn{6}{|c|}{ Kriteria Penelitian/ Research Point Criteria } & \multirow[b]{2}{*}{$V(A) 4$} & \multirow[b]{2}{*}{ UP } \\
\hline & $\mathrm{x} 1$ & V1(X1) & X2 & V2(X2) & x3 & V3(X3) & & \\
\hline $\begin{array}{l}\text { Rawai Hanyut/ } \\
\text { Drift Longline }\end{array}$ & $120,000,000$ & 1 & $2,000,000$ & 1 & 300,000 & 1 & 3 & 1 \\
\hline $\begin{array}{l}\text { Jaring Insang } \\
\text { Hanyut/ Drift } \\
\text { Gillnet }\end{array}$ & $96,000,000$ & 0.6 & $1,500,000$ & 0.5 & 200,000 & 0.33 & 1.43 & 2 \\
\hline $\begin{array}{l}\text { Bagan Tancap/ } \\
\text { Liftnet }\end{array}$ & $60,000,000$ & 0 & $1,000,000$ & 0 & 150,000 & 0 & 0 & 3 \\
\hline
\end{tabular}

Sumber : Data primer diolah, 2009.

Source : Primary data processed, 2009.

Keterangan :

$\mathrm{X} 1=$ Penerimaan kotor per tahun/ Bruto income per year

$\mathrm{V} 1(\mathrm{X} 1)=$ Nilai alat tangkap kali jumlah kriteria aspek/ Fishing gear value cross aspect criteria summary

$\mathrm{X} 2=$ Penerimaan kotor per trip/Bruto income per trip

$\mathrm{V} 1(\mathrm{X} 2)=$ Nilai alat tangkap kali jumlah kriteria aspek/ Fishing gear value cross aspect criteria summary

$\mathrm{X} 3=$ Penerimaan kotor per tenaga kerja/ Bruto income per employee

$\mathrm{V} 1(\mathrm{X} 3)=$ Nilai alat tangkap kali jumlah kriteria aspek/ Fishing gear value cross aspect criteria summary

$\mathrm{V}(\mathrm{A})^{4}=$ Hasil skoring/Scoring

UP $\quad=$ Urutan prioritas/ Priority 
Tabel 5. Skoring dan Standarisasi Fungsi Nilai Aspek Keramahan Lingkungan Unit Penangkapan Ikan Pelagis di Kabupaten Banyuasin.

Table 5. Scoring and Standardization of Environmental Friendly Value Function Aspect of Pelagic Fishing Unit in Banyuasin Regency.

\begin{tabular}{|c|c|c|c|c|c|c|c|c|c|c|c|}
\hline \multirow{3}{*}{$\begin{array}{c}\text { Unit } \\
\text { Penangkapan } \\
\text { Ikan Pelagis/ } \\
\text { Pelagic Fish } \\
\text { Fishing Units }\end{array}$} & \multicolumn{9}{|c|}{ Kriteria Penelitian/ Research Point Criteria } & \multirow{3}{*}{ VA5 } & \multirow{3}{*}{ UP } \\
\hline & $\mathbf{X 1}$ & $\mathbf{X} 2$ & X3 & $\mathrm{X} 4$ & $\mathrm{X} 5$ & X6 & $\mathrm{X7}$ & $\mathrm{x} 8$ & X9 & & \\
\hline & V1X1 & V2X2 & V3X3 & V4X4 & V5X5 & V6X6 & V7X7 & V8X8 & V9X9 & & \\
\hline \multirow{2}{*}{$\begin{array}{l}\text { Rawai Hanyut/ } \\
\text { Drift Longline }\end{array}$} & 2 & 4 & 4 & 4 & 4 & 2 & 4 & 4 & 1 & \multirow{2}{*}{6.33} & \multirow{2}{*}{1} \\
\hline & 1 & 1 & 1 & 0 & 1 & 0.33 & 1 & 1 & 0 & & \\
\hline \multirow{2}{*}{$\begin{array}{l}\text { Jaring Insang } \\
\text { Hanyut/ Drift } \\
\text { Gillnet }\end{array}$} & 2 & 4 & 4 & 4 & 3 & 4 & 3 & 3 & 4 & \multirow{2}{*}{5} & \multirow[t]{2}{*}{2} \\
\hline & 1 & 1 & 1 & 0 & 0 & 1 & 0 & 0 & 1 & & \\
\hline \multirow{2}{*}{$\begin{array}{l}\text { Bagan Tancap/ } \\
\text { Liftnet }\end{array}$} & 1 & 3 & 3 & 4 & 4 & 1 & 3 & 4 & 2 & \multirow{2}{*}{2.33} & \multirow{2}{*}{3} \\
\hline & 0 & 0 & 0 & 0 & 1 & 0 & 0 & 1 & 0.33 & & \\
\hline
\end{tabular}

Sumber : Data primer diolah, 2009.

Source : Primary data processed, 2009.

\section{Keterangan :}

$\mathrm{X} 1=$ Mempunyai selektivitas yang tinggi/ Having high selectivity

$\mathrm{V} 1(\mathrm{X} 1)=$ Nilai alat tangkap kali jumlah kriteria aspek/ Fishing gear value cross aspect criteria summary

X2 = Tidak merusak habitat/ Eco-friendly

$\mathrm{V} 1(\mathrm{X} 2)=$ Nilai alat tangkap kali jumlah kriteria aspek/ Fishing gear value cross aspect criteria summary

X3 = Menghasilkan ikan berkualitas tinggi/ High quality fish

$\mathrm{V} 1(\mathrm{X} 3)=$ Nilai alat tangkap kali jumlah kriteria aspek/ Fishing gear value cross aspect criteria summary

X4 = Tidak membahayakan nelayan/fisherman safety

$\mathrm{V} 1(\mathrm{X} 4)=$ Nilai alat tangkap kali jumlah kriteria aspek/ Fishing gear value cross aspect criteria summary

$\mathrm{X5}=$ Produksi tidak membahayakan konsumen/ Consumer safety

$\mathrm{V} 1(\mathrm{X} 5)=$ Nilai alat tangkap kali jumlah kriteria aspek/ Fishing gear value cross aspect criteria summary

X6 = By-catch rendah/Low By-catch

$\mathrm{V} 1(\mathrm{X} 6)=$ Nilai alat tangkap kali jumlah kriteria aspek/ Fishing gear value cross aspect criteria summary

$\mathrm{X7}=$ Dampak ke biodiversity/ Effect of biodiversity

$\mathrm{V} 1(\mathrm{X} 7)=$ Nilai alat tangkap kali jumlah kriteria aspek/ Fishing gear value cross aspect criteria summary

X8 = Tidak membahayakan ikan-ikan yang dilindungi/ Safety endangered fish

$\mathrm{V} 1(\mathrm{X} 8)=$ Nilai alat tangkap kali jumlah kriteria aspek/ Fishing gear value cross aspect criteria summary

X9 = Dapat diterima secara sosial/ Social acceptable

$\mathrm{V} 1(\mathrm{X9})=$ Nilai alat tangkap kali jumlah kriteria aspek/ Fishing gear value cross aspect criteria summary

$\mathrm{V}(\mathrm{A})^{5} \quad=$ Hasil skoring/ Scoring

UP $\quad=$ Urutan prioritas $/$ Priority

Analisis aspek biologi, teknis, sosial, ekonomi dan keramahan lingkungan

Berdasarkan hasil dari total standarisasi berdasarkan aspek biologi, teknis, sosial, ekonomi, dan keramahan lingkungan unit penangkapan ikan pelagis di Kabupaten
Banyuasin maka yang menjadi prioritas pengembangan adalah alat tangkap rawai hanyut pada urutan pertama, jaring insang hanyut pada urutan kedua dan bagan tancap pada urutan ketiga, dapat dilihat pada Tabel 6 . 
Tabel 6. Total Standarisasi Aspek Biologi, Teknis, Sosial, Ekonomi dan Keramahan Lingkungan Unit Penangkapan Ikan Pelagis di Kabupaten Banyuasin.

Table 6. Total Standardization of Biological, Technical, Social, Economical, and Environmental Friendly Aspect of Pelagic Fishing Unit in Banyuasin Regency.

\begin{tabular}{|c|c|c|c|c|c|c|c|}
\hline \multirow{2}{*}{$\begin{array}{c}\text { Unit Penangkapan Ikan } \\
\text { Pelagis/ Pelagic Fish } \\
\text { Fishing Units }\end{array}$} & \multicolumn{5}{|c|}{ Kriteria Penilaian/ Research Point Criteria } & \multirow{2}{*}{$\begin{array}{l}\text { V(A) } \\
\text { Total }\end{array}$} & \multirow[b]{2}{*}{ UP } \\
\hline & $V(A) 1$ & $V(A) 2$ & $V(A) 3$ & $V(A) 4$ & $V(A) 5$ & & \\
\hline $\begin{array}{l}\text { Rawai Hanyut/ Drift } \\
\text { Longline }\end{array}$ & 3 & 3 & 2 & 3 & 6.33 & 17.33 & 1 \\
\hline $\begin{array}{l}\text { Jaring Insang Hanyut/ } \\
\text { Drift Gillnet }\end{array}$ & 1.94 & 1.85 & 1.64 & 1.43 & 5 & 11.86 & 2 \\
\hline Bagan Tancap/ Liftnet & 0 & 0 & 1 & 0 & 2.33 & 3.33 & 3 \\
\hline
\end{tabular}

Sumber : Data primer diolah, 2009.

Source : Primary data processed, 2009.

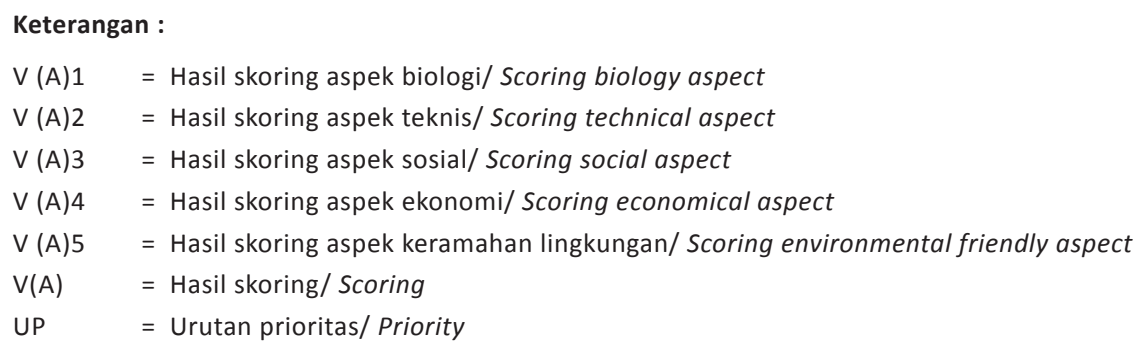

\section{ANALISIS FINANSIAL}

\section{Analisis usaha rawai hanyut}

Total penerimaan usaha Rp. 79.200 .000 dan biaya yang dikeluarkan Rp. 60.432.333, maka keuntungan Rp. 18.767.667. Nilai $R / C$ 1,31 , nilai ini lebih besar dari satu, artinya usaha ini menguntungkan. BEP 23.669,85 kg, artinya usaha ini akan menghasilkan keuntungan apabila telah memproduksi ikan 23.669,85 kg. ROI $41 \%$, investasi usaha perikanan rawai hanyut di Kabupaten Banyuasin layak dikembangkan.

\section{Analisis kriteria investasi rawai hanyut}

Nilai NPV Rp. 55.855.075, artinya nilai saat ini dari keuntungan yang akan diperoleh selama umur proyek 10 tahun di masa yang akan datang Rp. 55.855.075. Nilai Net B/C 2,22 , artinya setiap satu rupiah biaya yang dikeluarkan akan menghasilkan penerimaan
2 rupiah 22 sen selama umur proyek 10 tahun dengan suku bunga $15 \%$. IRR $48 \%$, artinya usaha proyek tersebut mampu memberikan tingkat pengembalian atau keuntungan $48 \%$ per tahun dari seluruh investasi yang ditanamkan selama umur proyek 10 tahun.

\section{Analisis sensitivitas rawai hanyut}

Asumsinya harga kenaikan minyak tanah dan solar terhadap penurunan harga ikan sangat berpengaruh dalam kegiatan usaha pengembangan perikanan.

Agar akurasi analisis semakin tinggi maka disertakan pula analisis sensitivitas untuk melihat pengaruh apa yang akan terjadi akibat perubahan harga input atau bahan baku yang akan berdampak pada nilai output diakhir perhitungan, dapat dilihat pada Tabel 7 dan Tabel 8. 
Tabel 7. Perbandingan Nilai Kriteria Investasi Akibat Kenaikan Harga Solar dan Minyak Tanah Sebesar 72,15\% pada Rawai Hanyut.

Table 7. Proportion Value of Investment Criteria Due to Increased in Diesel Fuel and Kerosene by $72.15 \%$ of the Drift Longline.

\begin{tabular}{ccccc}
\hline No & $\begin{array}{c}\text { Kriteria } \\
\text { Investasi/ } \\
\text { Criteria } \\
\text { Invest }\end{array}$ & $\begin{array}{c}\text { Sebelum Kenaikan Harga } \\
\text { Solar (Rp. 5.000) dan } \\
\text { Minyak Tanah (Rp. 3.000)/ } \\
\text { Before Prices Increasing of } \\
\text { Diesel Fuel (IDR. 5,000) and } \\
\text { Kerosene (IDR. 3,000) }\end{array}$ & $\begin{array}{c}\text { Sebelum Kenaikan Harga } \\
\text { Solar (Rp. 5.000) dan } \\
\text { Minyak Tanah (Rp. 3.000)/ } \\
\text { After Prices Increasing of } \\
\text { Diesel Fuel (IDR. 5,000) and } \\
\text { Kerosene (IDR. 3,000) }\end{array}$ & $\begin{array}{c}\text { Perubahan/ } \\
\text { Changing of } \\
\text { value }\end{array}$ \\
\hline 1 & NPV (Rp) & $55,855,075$ & $(68,290.79)$ & $55,923,365$ \\
2 & Net B/C & 2.22 & 0.9985 & 1.22 \\
3 & IRR $(\%)$ & $48 \%$ & $14.95 \%$ & $33.0 \%$ \\
\hline
\end{tabular}

Sumber : Data primer diolah, 2009.

Source : Primary data processed, 2009.

Tabel 8. Perbandingan Nilai Kriteria Investasi Akibat Penurunan Harga Ikan Sebesar 14,15\% pada Rawai Hanyut.

Table 8. Proportion Value of Investment Criteria Due to Decreased in Fish Price by $14.15 \%$ of the Drift Longline.

\begin{tabular}{ccccc} 
No & $\begin{array}{c}\text { Kriteria } \\
\text { Investasi/ } \\
\text { Criteria } \\
\text { Invest }\end{array}$ & $\begin{array}{c}\text { Sebelum Penurunan Harga } \\
\text { Ikan (Rp. 8,000) / Before } \\
\text { Decresing of Fish Prices } \\
\text { (IDR. 8,000) }\end{array}$ & $\begin{array}{c}\text { Sesudah Penurunan Harga } \\
\text { Ikan (Rp. 6,607.5)/ After } \\
\text { Decresing of Fish Prices } \\
\text { (IDR. 6,607.5) }\end{array}$ & $\begin{array}{c}\text { Perubahan/ } \\
\text { Changing } \\
\text { of Value }\end{array}$ \\
\hline 1 & NPV $(\mathrm{Rp})$ & $55,855,075$ & $(389,261.12)$ & $56,244,336$ \\
2 & Net B/C & 2.22 & 0.99 & 1.23 \\
3 & IRR $(\%)$ & $48 \%$ & $14.69 \%$ & $33.3 \%$ \\
\hline
\end{tabular}

Sumber : Data primer diolah, 2009.

Source : Primary data processed, 2009.

Analisis usaha jaring insang hanyut

Total penerimaan Rp. 64.000 .000 dan biaya yang dikeluarkan Rp. 46.680.000, maka keuntungan Rp. 17.320.000. Nilai $R / C$ 1,37, BEP volume pada usaha jaring insang hanyut $16.171,12 \mathrm{~kg}$, artinya usaha ini akan menghasilkan keuntungan apabila telah memproduksi ikan $16.171,12 \mathrm{~kg}$. ROI $40 \%$, investasi usaha perikanan jaring insang hanyut di Kabupaten Banyuasin layak dikembangkan.

Analisis kriteria investasi jaring insang hanyut

Nilai NPV Rp. 46.437.216, artinya nilai saat ini dari keuntungan yang akan diperoleh selama umur proyek 10 tahun di masa yang akan datang Rp. 46.437.216. Nilai Net B/C 2,08 , artinya setiap satu rupiah biaya yang dikeluarkan akan menghasilkan penerimaan 2 rupiah 08 sen selama umur proyek 10 tahun dengan suku bunga $15 \%$. IRR $47 \%$, artinya usaha proyek tersebut mampu memberikan tingkat pengembalian atau keuntungan $47 \%$ per tahun dari seluruh investasi yang ditanamkan selama umur proyek 10 tahun.

Analisis sensitivitas jaring insang hanyut. Hasil analisis sensitivitas menunjukkan bahwa apabila terjadi perubahan harga solar dan minyak tanah serta harga ikan, dapat dilihat pada Tabel 9 dan Tabel 10. 
Tabel 9. Perbandingan Nilai Kriteria Investasi Akibat Kenaikan Harga Solar dan Minyak Tanah Sebesar $\mathbf{4 1 \%}$ pada Jaring Insang Hanyut.

Table 9. Proportion Value of Investment Criteria Due to Increased in Diesel Fuel and Kerosene by $41 \%$ of the Drift Gillnet.

\begin{tabular}{ccccc}
\hline No & $\begin{array}{c}\text { Sebelum Kenaikan Harga } \\
\text { Investasi/ } \\
\text { Criteria } \\
\text { Invest }\end{array}$ & $\begin{array}{c}\text { Solar (Rp. 500) dan Minyak } \\
\text { Tanah (Rp. 3.000)/ Before } \\
\text { Prices Increasing of Die- } \\
\text { sel Fuel (IDR. 5,000) and } \\
\text { Kerosene (IDR. 3,000) }\end{array}$ & $\begin{array}{c}\text { Solar (Rp. 7.050) dan } \\
\text { Minyak Tanah (Rp. 4.230)/ } \\
\text { After Prices Increasing of } \\
\text { Diesel Fuel (IDR. 7, 050) and } \\
\text { Kerosene (IDR. 4,230) }\end{array}$ & $\begin{array}{c}\text { Perubahan/ } \\
\text { Changing of } \\
\text { Value }\end{array}$ \\
\hline 1 & NPV (Rp) & $46,437,216$ & $(217,458)$ & $46,654,674$ \\
2 & Net B $/ C$ & 2.08 & 0.99 & 1.09 \\
3 & IRR $(\%)$ & $47 \%$ & $14.80 \%$ & $32.2 \%$ \\
\hline
\end{tabular}

Sumber : Data primer diolah, 2009.

Source : Primary data processed, 2009.

Tabel 10. Perbandingan Nilai Kriteria Investasi Akibat Penurunan Harga Ikan Sebesar 15\% pada Jaring Insang Hanyut.

Table 10. Proportion Value of Investment Criteria Due to Decreased in Fish Price by $15 \%$ of the Drift Gillnet.

\begin{tabular}{ccccc}
\hline No & $\begin{array}{c}\text { Kriteria } \\
\text { Investasi/ } \\
\text { Criteria } \\
\text { Invest }\end{array}$ & $\begin{array}{c}\text { Sebelum Penurunan Harga } \\
\text { Ikan (Rp. 8.000)/ Before } \\
\text { Decresing of Fish Prices } \\
\text { (IDR. 8,000) }\end{array}$ & $\begin{array}{c}\text { Sesudah Penurunan } \\
\text { Harga Ikan (Rp. 6.800)/ } \\
\text { After Decresing of Fish } \\
\text { Prices (IDR. 6,800) }\end{array}$ & $\begin{array}{c}\text { Perubahan/ } \\
\text { Changing of } \\
\text { Value }\end{array}$ \\
\hline 1 & NPV (Rp) & $46,437,216$ & $(1,742,963)$ & $48,180,179$ \\
2 & Net B/C & 2.22 & 0.99 & 1.23 \\
3 & IRR $(\%)$ & $48 \%$ & $13.36 \%$ & $34.64 \%$ \\
\hline
\end{tabular}

Sumber : Data primer diolah, 2009.

Source : Primary data processed, 2009.

Analisis usaha bagan tancap

Penerimaan Rp. 79.800 .000 dan biaya yang dikeluarkan Rp. 49.190.000, maka keuntungan Rp. 23.610.000. Nilai $R / C$ 1,48. BEP $16.506 \mathrm{~kg}$, artinya usaha ini akan menghasilkan keuntungan apabila telah memproduksi ikan $16.506 \mathrm{~kg}$. ROI $32 \%$, artinya investasi usaha perikanan bagan tancap di Kabupaten Banyuasin layak dikembangkan.

\section{Analisis kriteria investasi bagan tancap}

Nilai NPV Rp. 214.477.312, artinya nilai saat ini dari keuntungan yang akan diperoleh selama umur proyek 10 tahun di masa yang akan datang Rp. 214.477.312. Nilai Net B/C 3,94 , artinya setiap satu rupiah biaya yang dikeluarkan akan menghasilkan penerimaan 3 rupiah 94 sen selama umur proyek 10 tahun dengan suku bunga $15 \%$. IRR $83 \%$, artinya usaha proyek tersebut mampu memberikan tingkat pengembalian atau keuntungan $83 \%$ per tahun dari seluruh investasi yang ditanamkan selama umur proyek 10 tahun.

Analisis sensitivitas bagan tancap, hasil analisis sensitivitas menunjukkan bahwa apabila terjadi perubahan harga solar dan minyak tanah serta harga ikan, maka kriteria investasi akan mengalami perubahan, dapat dilihat pada Tabel 11 dan Tabel 12. 
Tabel 11. Perbandingan Nilai Kriteria Investasi Akibat Kenaikan Harga Solar dan Minyak Tanah Sebesar $93 \%$ pada Bagan Tancap.

Table 11. Proportion Value of Investment Criteria Due to Increased in Diesel Fuel and Kerosene by $93 \%$ of the Liftnet.

\begin{tabular}{ccccc}
\hline No & $\begin{array}{c}\text { Kriteria } \\
\text { Investasi/ } \\
\text { Criteria } \\
\text { Invest }\end{array}$ & $\begin{array}{c}\text { Solar (Rp. 5000) dan Minyak } \\
\text { Tanah (Rp. 3000)/ Before } \\
\text { Prices Increasing of Diesel } \\
\text { Fuel (IDR. 5,000) and } \\
\text { Kerosene (IDR. 3,000) }\end{array}$ & $\begin{array}{c}\text { Sesudah Kenaikan Harga } \\
\text { Solar (Rp. 9.650) dan } \\
\text { Minyak Tanah (Rp. 5.790)/ } \\
\text { After Prices Increasing of } \\
\text { Diesel Fuel (IDR. 9,650) and } \\
\text { Kerosene (IDR. 5,790) }\end{array}$ & $\begin{array}{c}\text { Perubahan/ } \\
\text { Changing of } \\
\text { Value }\end{array}$ \\
\hline 1 & NPV (Rp) & $214,477,312$ & $(348,422)$ & $214,825,734$ \\
2 & Net B/C & 3.94 & 0.995 & 2.95 \\
3 & IRR (\%) & $83 \%$ & $14.83 \%$ & $68.17 \%$ \\
\hline
\end{tabular}

Sumber : Data primer diolah, 2009.

Source : Primary data processed, 2009.

Tabel 12. Perbandingan Nilai Kriteria Investasi Akibat Penurunan Harga Ikan Sebesar $18,5 \%$ pada Bagan Tancap.

Table 12. Proportion Value of Investment Criteria Due to Decreased in Fish Price by $18.5 \%$ of the Liftnet.

\begin{tabular}{ccccc}
\hline No & $\begin{array}{c}\text { Kriteria } \\
\text { Investasi/ } \\
\text { Criteria } \\
\text { Invest }\end{array}$ & $\begin{array}{c}\text { Sebelum Penurunan } \\
\text { Harga Ikan (Rp. 8,000)/ } \\
\text { Before Decresing of Fish } \\
\text { Prices (IDR. 8,000) }\end{array}$ & $\begin{array}{c}\text { Sesudah Penurunan Harga } \\
\text { Ikan (Rp.6,520)/ After } \\
\text { Decresing of Fish Prices } \\
\text { (IDR. 6,520) }\end{array}$ & $\begin{array}{c}\text { Perubahan/ } \\
\text { Changing of } \\
\text { Value }\end{array}$ \\
\hline 1 & NPV (Rp) & $214,477,312$ & $(87,497)$ & $214,564,809$ \\
2 & Net B/C & 3.94 & 0.99 & 2.95 \\
3 & IRR $(\%)$ & $83 \%$ & $14.96 \%$ & $68.04 \%$ \\
\hline
\end{tabular}

Sumber : Data primer diolah, 2009.

Source : Primary data processed, 2009.

\section{Analisis Optimasi}

Hasil analisis ini menunjukkan bahwa alokasi unit penangkapan ikan pelagis yang dominan di perairan Sungsang dapat dilihat pada Tabel 13.

Alokasi jumlah unit penangkapan rawai hanyut yang optimum di Sungsang adalah sebanyak 51 unit. Jumlah tersebut mengalami penambahan sebanyak 31 unit dari jumlah yang ada sekarang yaitu sebanyak 20 unit. Hal ini juga menunjukkan bahwa terjadi peningkatan jumlah unit penangkapan. Sedangkan jumlah alat tangkap jaring insang hanyut yang ada di Kabupaten Sungsang adalah 90 unit maka dilakukan pembatasan sebesar 45 unit dan alat tangkap bagan tancap yang ada dewasa ini sebesar 110 unit dialokasikan menjadi 55 unit hal ini dilakukan untuk mentransfer teknologi secara bertahap alat penangkapan ikan dari alat yang ada ke alat penangkapan ikan yang baik.

Selain penambahan jumlah armada, yang seharusnya dilakukan adalah dengan memperluas jangkauan kapal dan memperbaiki struktur usaha melalui peningkatan sumberdaya manusia (SDM) serta dengan jumlah nelayan atau tenaga kerja yang terlalu banyak harus dilakukan reposisi atau beralih profesi seperti budidaya laut, pengolahan ikan dikarenakan jumlah nelayan yang banyak sedangkan areal penangkapan yang kecil dan sumberdaya ikan yang hampir habis (overfishing). Pada perikanan yang sudah tereksploitasi pengaruh yang paling besar adalah kegiatan penangkapan (Badrudin dan Sumiono 2002). 
Tabel 13. Alokasi Unit Penangkapan Ikan Pelagis. Table 13. Allocation of Pelagic Fishing Unit.

\begin{tabular}{clcc}
\hline No & Alat Tangkap/ Fishing Gears & $\begin{array}{c}\text { Unit Penangkapan } \\
\text { yang Ada/ Fishing } \\
\text { Units }\end{array}$ & $\begin{array}{c}\text { Alokasi Alat Tangkap } \\
\text { Optimum/ Optimum } \\
\text { Allocated Fishing Gears }\end{array}$ \\
\hline 1 & Rawai Hanyut/ Drift Longline & 20 & 51 \\
2 & Jaring Insang Hanyut/ Drift Gillnet & 90 & 45 \\
3 & Bagan Tancap/ Liftnet & 110 & 55 \\
\hline
\end{tabular}

Sumber : Data primer diolah, 2009.

Source : Primary data processed, 2009.

\section{STRATEGI PENGEMBANGAN PERIKANAN TANGKAP BERBASIS SUMBERDAYA IKAN PELAGIS}

Kebijakan pengelolaan sumberdaya pesisir dan laut yang disusun, hendaknya didasari atau mempertimbangkan empat aspek/dimensipembangunan berkelanjutan, yaitu aspek biologi, aspek teknis, aspek sosial, aspek ekonomi dan keramahan lingkungan. Oleh karena itu, di dalam penelitian ini analisis kebijakan yang didasarkan atas faktor-faktor eksternal dan internal dilakukan dengan mempertimbangkan keempat aspek tersebut, dapat dilihat pada Tabel 14.

Analisis SWOT didasarkan pada asumsi bahwa strategi yang efektif adalah dengan memaksimalkan kekuatan (strengths) dan peluang (opportunities), serta meminimalkan kelemahan (weaknesses) dan ancaman (threats).

Strategi pengembangan perikanan pelagis yang didasarkan pada potensi yang dimiliki Sungsang (Strategi SO) diarahkan pada optimalisasi usaha perikanan pelagis (Tabel 15). Strategi ST diarahkan pada pengembangan usaha perikanan pelagis di jalur 2 (6 - 12 mil) (Tabel 15). Strategi WO adalah peluang pengembangan yang harus ada intervensi dari luar untuk pelaksanaannya. Strategi tersebut adalah peningkatan manajemen usaha perikanan pelagis dan pembenahan fasilitas sarana dan prasarana perikanan (Tabel 15). Strategi WT adalah pengembangan untuk mengatasi kekurangan-kekurangan yang dimiliki oleh Sungsang dan ancaman yang dapat ditimbulkannya. Strateginya yaitu peningkatan skala usaha armada penangkapan ikan pelagis (Tabel 15).

Pengembangan kegiatan perikanan tangkap harus diarahkan pada peningkatan kapasitas armada dan teknologi penangkapan untuk dapat mencapai fishing ground yang lebih jauh dalam rangka mengurangi tekanan stok di perairan fishing ground yang ada sekarang, untuk itu perlu didukung penyediaan sarana dan prasarana tangkap serta peningkatan teknologi penanganan dan pengolahan hasil perikanan (Nikijuluw et al., 2003). 
Tabel 14. Identifikasi, Skoring dan Arahan Pengembangan Perikanan Pelagis. Table 14. Identification, Scoring and Development Direction for Pelagic Fishery.

\begin{tabular}{|c|c|c|c|}
\hline $\begin{array}{l}\text { Kode/ } \\
\text { Code }\end{array}$ & Identifikasi SWOT/ SWOT Identification & $\begin{array}{l}\text { Skor/ } \\
\text { Score }\end{array}$ & $\begin{array}{c}\text { Kemungkinan Pengembangan/ } \\
\text { Development Possibility }\end{array}$ \\
\hline \multicolumn{4}{|c|}{ Kekuatan (Strengths) } \\
\hline S1 & $\begin{array}{l}\text { Potensi sumberdaya perikanan tangkap } \\
\text { cukup tersedia/ Catch potension is } \\
\text { available }\end{array}$ & 3 & $\begin{array}{l}\text { Pemanfaatan sumberdaya ikan } \\
\text { pelagis secara rasional/ Utilization of } \\
\text { pelagic fish rasionaly }\end{array}$ \\
\hline $\mathrm{S} 2$ & $\begin{array}{l}\text { Sumberdaya nelayan cukup tersedia/ } \\
\text { Fisherman is obtainable }\end{array}$ & 3 & $\begin{array}{l}\text { Peningkatan kualitas sumberdaya } \\
\text { nelayan secara optimal/ Quality } \\
\text { abgrading of fisherman optimaly }\end{array}$ \\
\hline S3 & $\begin{array}{l}\text { Adanya dukungan pemerintah daerah } \\
\text { dalam sub sektor perikanan tangkap/ } \\
\text { Local government support in sub sector of } \\
\text { capture fisheries }\end{array}$ & 2 & $\begin{array}{l}\text { Inventarisasi kapal perikanan dan } \\
\text { proyek pengelolaan sumberdaya } \\
\text { kelautan dan perikanan/ Fishing } \\
\text { gears inventarisation and marine n } \\
\text { fisheries management project }\end{array}$ \\
\hline \multicolumn{4}{|c|}{ Kelemahan (Weaknesses) } \\
\hline W1 & $\begin{array}{l}\text { Masih beroperasi di dekat pantai/ Fishing } \\
\text { gears operated in shore }\end{array}$ & 5 & $\begin{array}{l}\text { Penyediaan armada penangkapan } \\
\text { dijalur } 2 \text { / Fishing gear accessable in } \\
\text { line second }\end{array}$ \\
\hline W2 & $\begin{array}{l}\text { Mutu hasil tangkapan rendah/ Quality of } \\
\text { catches is low }\end{array}$ & 3 & $\begin{array}{l}\text { Bimbingan atau pembinaan } \\
\text { penanganan dan pengolahan } \\
\text { hasil perikanan/ Empowerment } \\
\text { of fish handling and management } \\
\text { processed }\end{array}$ \\
\hline W3 & $\begin{array}{l}\text { Terbatasnya modal usaha/ Modal usaha is } \\
\text { limited }\end{array}$ & 4 & $\begin{array}{l}\text { Membantu pemberian modal usaha/ } \\
\text { Assist of modal usaha }\end{array}$ \\
\hline W4 & $\begin{array}{l}\text { Sarana dan prasarana perikanan minim/ } \\
\text { Limited of infrastructure }\end{array}$ & 4 & $\begin{array}{l}\text { Memperbaiki dan melengkapi } \\
\text { sarana dan prasarana/ Fixing and } \\
\text { completing of infrastructure }\end{array}$ \\
\hline W5 & $\begin{array}{l}\text { Rendahnya tingkat pendidikan nelayan } \\
\text { dan manajemen usaha yang lemah/ Low } \\
\text { education of fisherman and weakness of } \\
\text { effort management }\end{array}$ & 3 & $\begin{array}{l}\text { Peningkatan kualitas nelayan dengan } \\
\text { pelatihan / penyuluhan/ Fisherman } \\
\text { educated added by workshop }\end{array}$ \\
\hline \multicolumn{4}{|c|}{ Peluang (Opportunities) } \\
\hline 01 & $\begin{array}{l}\text { Akses ke kota Palembang cukup lancar/ } \\
\text { Acces to palembang is easy }\end{array}$ & 4 & $\begin{array}{l}\text { Peningkatan produksi perikanan/ } \\
\text { Raising of fisheries production }\end{array}$ \\
\hline $\mathrm{O} 2$ & $\begin{array}{l}\text { Harga ikan pelagis meningkat/ Improving } \\
\text { of pelagic fish prices }\end{array}$ & 3 & $\begin{array}{l}\text { Peningkatan produksi perikanan ikan } \\
\text { pelagis/ Raising of pelagic fisheries } \\
\text { production }\end{array}$ \\
\hline $\mathrm{O3}$ & $\begin{array}{l}\text { Peningkatan permintaan pasar/ Enchancing } \\
\text { ofmarket demand }\end{array}$ & 3 & $\begin{array}{l}\text { Identifikasi permintaan pasar/ } \\
\text { Market demand identification }\end{array}$ \\
\hline \multicolumn{4}{|c|}{ Ancaman (Threats) } \\
\hline $\mathrm{T} 1$ & $\begin{array}{l}\text { Keamanan di laut akibat perampokan/ Sea } \\
\text { savety caused by criminal }\end{array}$ & 3 & $\begin{array}{l}\text { Peningkatan keamanan di laut/ } \\
\text { Enlarging of sea savety }\end{array}$ \\
\hline $\mathrm{T} 2$ & $\begin{array}{l}\text { Nelayan skala sedang-besar masuk } \\
\text { perairan pantai (IUU Fishing)/ Medium and } \\
\text { big scale fisherman is entering in shore }\end{array}$ & 4 & $\begin{array}{l}\text { Pembatasan jumlah kapal dan hasil } \\
\text { tangkapan/ Fishing gears and catch } \\
\text { prohibit }\end{array}$ \\
\hline T3 & Harga BBM tinggi/ Fuel price is allowated & 3 & $\begin{array}{l}\text { Penggunaan alat tangkap yang } \\
\text { hemat bahan bakar/ Low fuel fishing } \\
\text { gears }\end{array}$ \\
\hline
\end{tabular}


Tabel 15. Analisis Keterkaitan Antar Unsur SWOT

Table 15. Interconnection Analysis of the SWOT

\begin{tabular}{|c|c|c|c|}
\hline No & $\begin{array}{l}\text { Unsur SWOT/ } \\
\text { SWOT Part }\end{array}$ & Keterkaitan/ Connection & $\begin{array}{c}\text { Jumlah/ } \\
\text { Value }\end{array}$ \\
\hline \multicolumn{4}{|c|}{ Strategi SO/ SO-Strategy } \\
\hline 1 & SO3 & $\begin{array}{l}\text { Optimalisasi usaha perikanan pelagis/ Fisheries effort } \\
\text { optimalization } \\
\mathrm{S} 1, \mathrm{~S} 2, \mathrm{~S} 3, \mathrm{O} 1, \mathrm{O} 2, \mathrm{O} 3\end{array}$ & 22 \\
\hline \multicolumn{4}{|c|}{ Strategi ST/ ST-Strategy } \\
\hline 2 & ST2 & $\begin{array}{l}\text { Pengembangan usaha perikanan pelagis di jalur } 2 \text { (6 - } 12 \\
\text { mil)/ Development pelagic fish effort in line second } \\
\mathrm{S} 1, \mathrm{~S} 2, \mathrm{~S} 3, \mathrm{~T} 1, \mathrm{~T} 2, \mathrm{~T} 3\end{array}$ & 19 \\
\hline \multicolumn{4}{|c|}{ Strategi wo/ wo-Strategy } \\
\hline 3 & W03 & $\begin{array}{l}\text { Peningkatan manajemen usaha perikanan pelagis/ } \\
\text { Emplifying pelagic fisheries } \\
\text { W2, W3, W5, O2, } 03\end{array}$ & 16 \\
\hline 4 & W01 & $\begin{array}{l}\text { Pembenahan fasilitas sarana dan prasarana perikanan/ } \\
\text { Fixing of fisheries infrastructure } \\
\text { W4, } \mathrm{O} 1, \mathrm{O} 3\end{array}$ & 11 \\
\hline \multicolumn{4}{|c|}{ Strategi WT/ WT-Strategy } \\
\hline 5 & WT1 & $\begin{array}{l}\text { Peningkatan skala usaha armada penangkapan ikan } \\
\text { pelagis/ Augementing of pelagic fish scale attempt } \\
\mathrm{W} 1, \mathrm{~T} 1, \mathrm{~T} 2, \mathrm{~T} 3\end{array}$ & 15 \\
\hline
\end{tabular}

\section{PENUTUP}

Teknologi penangkapan ikan pelagis yang efektif, efisien dan berkelanjutan adalah rawai hanyut karena rawai hanyut ramah terhadap lingkungan, sehingga kelestarian sumber daya ikan di Kabupaten Banyuasin tetap terjaga, alokasi jumlah unit penangkapan optimum adalah rawai hanyut sebesar 51 unit, jaring insang hanyut 45 unit dan bagan tancap 55 unit berarti alat tangkap rawai hanyut harus ditingkatkan daripada alat tangkap yang lainnya, dan strategi pengembangan alat tangkap ikan pelagis adalah : 1) Optimalisasi usaha perikanan pelagis dengan rawai hanyut: 2 ) Pengembangan usaha perikanan pelagis di jalur 2 ; 3) Peningkatan manajemen usaha perikanan pelagis dan Pembenahan fasilitas sarana dan prasarana perikanan; dan 4) Peningkatan skala usaha armada penangkapan rawai hanyut.

\section{DAFTAR PUSTAKA}

Anonimous. 2006. Laporan Tahunan Dinas Perikanan dan Kelautan Kabupaten Banyuasin. Kabupaten Banyuasin. Propinsi Sumatera Selatan. HIm 164.

Ayodhyoa, A.U. 1981. Metode Penangkapan Ikan. Yayasan Dewi Sri. Bogor. HIm 81.

Badrudin, M. dan B. Sumiono. 2002. Indeks Kelimpahan Stok dan Proporsi Udang dalam Komunitas Sumberdaya Demersal di Perairan Kepulauan Aru, Laut Arafura. Jurnal Penelitian Perikanan Indonesia. Badan Riset Kelautan dan Perikanan. Volume 8: hal 95-100.

Kadariah, L. Karlina dan C. Grey. 1981. Pengantar Evaluasi Proyek. Edisi Revisi. Lembaga Penerbit FE-UI. Jakarta. HIm 181. 
Mangkusubroto, K. dan C.L. Trisnadi. 1985. Analisa Keputusan Pendekatan Sistem dalam Manajemen Usaha dan Proyek. Ganeca Exact. Bandung. HIm 271.

Nikijuluw, V.P.H., D.G. Bengen dan M. Rifqi. 2003. Guidelines and Strategy for The Development of Coastal Fisheries in The District of Padang Pariaman. Jurnal Penelitian Perikanan Indonesia. Vol. 9: hal 75-103.

Sadhori, N. 1985. Tehnik Penangkapan Ikan. Penerbit Angkasa. Bandung. HIm 13-23.
Samuel. 2003. Composition of Species Caught by Some Fishing Gears in The Middle Part of Musi River Basins. Jurnal IImuilmu Perikanan dan Budidaya Perairan Indonesia, Volume 1: hal 89-100.

Siswanto, 1993. Goal Programming dengan menggunakan LINDO. PT Elex Media Komputindo Kelompok Gramedia Jakarta.

Stevenson, W.J. 1989. Introduction to Management Science. Homewood. Boston. 